\title{
DEVELOPMENT OF A HYPOTHETICAL BACCALAUREATE PROGRAM IN DENTAL HYGIENE EMPHASIZING THE COMMUNITY *
}

\author{
Dolores M. Malvitz, RDH, DrPH+
}

The task of developing a curriculum model for baccalaureate education in community dental hygiene proved to be an assignment far more difficult than first anticipated. Hopefully, the product which resulted from those efforts will stimulate discussion here - that is, after all, its primary purpose. The curriculum model proposed is essentially a dental hygiene "major" and a minor within another academic discipline - preferably one of the social or behavioral sciences. Rather than examine only that final product, it seems reasonable to describe the processes by which it was created.

Like a true "public healther," my initial response to the problem of developing a curriculum was to conduct a survey. Actually, several surveys were carried out - of dental hygienists, dental hygiene educators, potential employers of these "community dental hygienists," nurses, public health workers, and, of course, books of all kinds. $5,6,7,8,13,15,16$ Those surveying activities did not provide instant answers and, in fact, they created some new questions. The issue of training versus education was resolved by choosing to emphasize the higher cognitive process implied by the word "education" rather than the development of specific technical skills usually associated with "training." Still, that decision could hardly be called a breakthrough, given the title of this conference.

\section{Certification}

The surveys highlighted another, perhaps more troublesome, distinction - the one between education and certification: between learning to "be" a professional and being credentialed as competent in that profession. For most professions, the two are intertwined as functions of the educational institutions - one could say that such is the case for dental hygiene itself. Although formal certification for practice is the prerogative of the individual state licensing boards, only one state does not require education in an accredited institution in order to be eligible for the licensing examination. Such is not the case for community dental hygiene, however. Currently, no consistent mechanism exists to control entry to the practice of community dental hygiene. Because few potential employers seem to recognize the additional skills and knowledge needed by such a hygienist, all job descriptions do not delineate educational attainment at a specific level. Even when the job description does mention a baccalaureate, supervisors may hire a dental hygienist without that degree. Not many seem to have followed the suggestions made nearly 20 years ago in the American Public Health Association's Educational Qualifications of Public Health Dental Hygienists. ${ }^{9}$

Perhaps the lack of community positions might be the source of this apparent indifference. In my own state a survey of all licensed hygienists was conducted this past summer - 90 percent responded to the mailed questionnaire. ${ }^{14}$ Of those respondents, only 5.8 percent reported that they spent any of their professional time in jobs categorized as "public schools," "governmental agency" or "other" - the nonprivate-practice, nondental-hygiene faculty alternatives in that question. An even smaller proportion was employed in such positions full time - just 3.6 percent. When so few community positions exist, is it surprising that low priority is assigned to standing at the gate, monitoring who is hired? What organizations might choose to assume a gatekeeping role for community dental hygiene? More

\footnotetext{
'Presented at the Invitational Conference on Baccalaureate Dental Hygiene Education, Iowa City, Iowa, December 10, 1975.

+Assistant Professor of Dental Public Health, School of Public Health, The University of Michigan, Ann Arbor, Michigan 48109.
} 
important, which might have the power to do so? Dental hygienists' associations? State boards of dentistry? Educational institutions? American Public Health Association?

Most might agree that there is little likelihood of recognition by formal certification for community dental hygiene, in the near future at least. Since entry into the practice of community dental hygiene will not be regulated, there will continue to be practitioners of that art whose degrees range from associate to master, and whose skills and understandings also vary greatly. Although certainly a frustrating state of affairs, dental hygiene is not the only profession in this quandary. Public health nurses, head nurses in hospitals, and dentists in public health or administrative positions all share the dilemma. Among the professional groups currently grappling with the certification issue are health educators. In the ranks of those answering to the title "health educator" are community aides without high school diplomas as well as those holding doctoral degrees in health education, and nearly every educational level in between. Although all types of institutions purport to train professional health educators, accreditation mechanisms focus only on masters' level programs. So ... it could be worse in dental hygiene, perhaps. Nevertheless, the reality is that, until some way is found to regulate who is employed as a "community dental hygienist," developing baccalaureate programs to educate such persons is a hypothetical exercise.

\section{Duties and Role Definition}

The next problem encountered was trying to define exactly what this "community dental hygienist" would do. What skills would this person need? What is the community in which the individual would function? Should this hygienist be doing the same things with greater proficiency or entirely different "things"? In trying to answer this set of questions, it seemed clear that the traditional communities we have served in the past - albeit in limited fashion - are extremely likely to be changing. How will the advent of HSAs (Health Service Areas) alter the traditional city or county health departments? Will Neighborhood Health Centers survive the Ford administration's vetoes? What about other acronyms - HMOs, PSROs, VISTA, EPSDT? Might group practices, intermediate school districts, third-party carriers, or organized dental hygiene also constitute "communities"? The dictionary definition of "community" encourages one to continue thinking along those lines. It indicated a community could be all of the following: 1) a group of people living in the same locality and under the same government; 2) a social group or class having common interests; 3) similarity or identity [community of interests]; 4) society as a whole; 5) common possession or participation. ${ }^{1}$ That so many organizational entities and unorganized groups might fit the definition of community reinforced use of the broadest interpretation of "community" as a basis for developing the curriculum model.

Next came the problem, would this baccalaureate community dental hygienist need clinical skills as highly developed and refined as the noncommunity person? Or, since this hygienist would not be functioning "at the chair," would it be enough to provide a foundation for and understanding of those clinical skills and minimal practice, then focus the majority of attention on learning which can be provided only by a baccalaureate institution? Should we try to create superpersons who can do everything connoted by "dental hygienist" and do it well, or might we be content with a division of labor? Should every community hygienist be a generalist with the same mix of specialized skills, or should both depth and diversity be encouraged among those who are graduated from such a hypothetical curriculum? Because any "community" will require this hygienist to function within its structure and indeed, to identify what that structure is - this person would seem to need greater, deeper knowledge of the behavioral and social sciences. "Public health" is already an applied science; today it is grounded less in the natural and biological sciences than in the social and behavioral ones. (Increasingly, health administrators and those who are admitted to schools of public health have backgrounds strong in the social sciences and humanities, rather than the traditional biologically based health occupations. As health problems focus more and 
more on the application of knowledge already possessed, that trend will continue.) Are there not many academic disciplines which might be appropriate for community dental hygienists? Indeed, is the need for a foundation in the behavioral and social sciences not already as important as such basic preparation in the biological sciences? Will this need not be accentuated when - and if - educational institutions acknowledge that health care is a right, not a privilege accorded only a few who can afford to pay for it?

\section{A Proposed Curriculum}

Ideally, the specific functions of the community dental hygienist would be listed, then a curriculum planned on the basis of those proposed activities and objectives. However, because we simply do not know what the specific responsibilities of this hygienist will be in the uncertain future, no attempt has been made to identify exact functions. It does seem clear that the baccalaureate community worker would not be occupying upper level administrative, planning, or research positions - such jobs will continue to require the more substantial knowledge provided by advanced degrees. Such persons would "diagnose" problems, and delegate selected aspects of program development, implementation and evaluation to the baccalaureate community hygienist who would be responsible for completing the unit of work assigned, making necessary decisions for that aspect of the program. Major program decisions will not be within the scope of responsibility of those holding only the baccalaureate degree; therefore, that degree should not attempt to duplicate, in "watered-down" fashion, what is offered in masters and doctoral level education. Rather, baccalaureate programs should provide entry-level skills at planning, implementing, and evaluating programs (or portions of programs) - a foundation upon which further skills and responsibility can be developed by subsequent education.

As I began pouring through college catalogs, an even more heretical thought began to take shape. If baccalaureate programs in occupational therapy, physical therapy, speech pathology, medical technology, and social work can provide basic, beginning level competence in the discipline with 30-38 semester hours in the major subject, why can't dental hygiene do the same? Perhaps the criterion might be the question: "What do we dare not teach?" A careful pruning would permit accumulating a minor in another discipline. Would such a cadre of persons with varying skills, reflecting their own interests, not add immeasurably to scholarship and creativity in dental hygiene? Is there not a precedent for such an approach set by dental schools which provide a head start on graduate education by abbreviating clinical practice?

At this point, firm decisions about hypothetical curriculum still had not been made, and all the surveying had only initiated more questions. So, it was arbitrarily assumed:

1) A baccalaureate program in community dental hygiene would not be the only option open to a person interested in dental hygiene - that is, there would be programs emphasizing clinical skills available to a potential student who wished to pursue a particular alternative.

2) There might be many communities in which a dental hygienist could function effectively today's educators and practitioners have scant idea of all future potential communities. In whatever "community" the community dental hygienist works, it will be crucial to understand human behavior - both individual and organizational - and the social and political forces which determine health policy; then to identify how each of these might be altered or used as the basis for planning programs to maintain and enhance health.

3) Since, in the foreseeable future, entry to community dental hygiene positions will not be controlled, it is imperative that the baccalaureate hygienist demonstrate skill and knowledge of working with others well beyond the level of nonbaccalaureate persons. In addition, these community hygienists will need enough confidence in their own abilities that they can convince potential employers of their value.

4) Basic competence in clinical dental hygiene skills can be developed in a 30-35 hour major sequence, of which a substantial portion could focus on community aspects of dental hygiene practice. 
5) The program should allow - even encourage - students to pursue their own interests in some depth, rather than dictating a lock-step sequence that all community dental hygiene students must follow.

6) Whenever possible, social and behavioral science theory should come from the parent academic disciplines rather than being filtered through dental hygiene faculty.

7) The program should not be structured in a way which completely closes out associate hygienists who have decided they want to continue their educations in dental hygiene. Because two-year programs are now - and are likely to remain - the mode in dental hygiene education, it would be foolish to restrict those who want to advance themselves. (Associate level programs might well serve as a valuable filtering mechanism, with the best qualified students' electing to pursue baccalaureate degrees and greater responsibility.) Since the focus of this curriculum is the community, no attempt need be made to reevaluate the clinical competence of such applicants. In addition, it should be possible for a student to attend on a part-time basis.

8) Specifically, for this hypothetical program, students would be admitted as freshmen, advised of prerequisite courses to be elected during the first two years, then reviewed for acceptable academic performance at the end of the sophomore year, before being allowed to register for basic dental hygiene courses. Transfer students would be admitted and evaluated in the same way, and given advanced standing when appropriate. Although students would be encouraged to choose one of the social sciences as a minor, those who elected humanities, education, or business administration courses would neither be rejected nor kept from graduating if other prerequisites had been met. It also seems important to provide students with practice synthesizing and applying knowledge gained in basic social science coursework to problems unique to dentistry and dental hygiene.

\section{Dental Hygiene in "University $X$ "}

A university - not my own - was then chosen. Within its various requirements, and using its existing courses, the baccalaureate curriculum in community dental hygiene was planned. This institution offers baccalaureate and graduate programs, as well as several professional curricula, but has neither a college of dentistry nor a dental hygiene program. It functions on a semester system and delineates fairly general requirements for a bachelor's degree. "University X" also has some not unusual broad educational goals: 1) to develop in each student the ability to think objectively and critically, so that he may be capable of assessing the validity of the information with which he is confronted and his own response to his environment; 2) to introduce him to the world in which the educated and responsible citizen lives; 3) to provide with him a foundation for tenable values; and 4) to provide each student with sufficient knowledge in a discipline, or a group of related disciplines, so that he will have an understanding of its methodology, some initial competence in the field and an appreciation of the vastness of the knowledge still to be explored.

Since the curriculum is really nothing more than allowing students to "major" in community dental hygiene while "minoring" in another academic discipline and, since no two such students' programs might be alike, it is impossible to give detailed descriptions of the curriculum. An example can be provided, however, and that is done. My student (let's call him - or her - Leslie Smith) has decided to "minor" in sociology, and the courses chosen reflect Leslie's interests as well as meeting the sociology department's requirements for a minor. Leslie could as likely be a minor in political science, economics, psychology or, for that matter, business administration, nutrition, or statistics. It is suggested that a course examining research methodology in some detail be an important part of any student's minor coursework, for an ability to evaluate critically what one reads is a vital part of professional practice, especially when one is responsible to a community. Leslie has attended classes with other students of sociology, benefiting from the cross-fertilization of ideas inherent in that arrangement. Simultaneously, Leslie has been enrolled in dental hygiene courses, meeting the requirements of the community dental hygiene department. Descriptions of the three courses (totaling 13 of the 32 credit hours) which specifically focus on community dental hygiene seem warranted. 
DH 350 Community Dental Hygiene, 3 credit hours ( 3 clock hours)

Survey of current community health problems, the relation of dental health to total health, and evaluation of community, preventive methods, including health education. Emphasis on the use of tools such as epidemiology and biostatistics and on the process of defining a problem, planning, executing, and evaluating programs. Attention to population patterns, organization and financing of health care, and the relation of legislative and socioeconomic trends to health, especially dental health.

DH 410 Synthesis Seminar, 4 credit hours (3 clinical hours, 3 seminar hours)

Review and analysis of behavioral and social and social science foundations of healthrelated behavior. Development of conceptual basis for understanding, predicting, and facilitating change in health-related behaviors, especially dental. Clinical assignments with special client groups and case studies will be the basis for seminar sessions designed to integrate and synthesize theory from the minor disciplines represented by students enrolled.

DH 420 Community Practice Seminar, 6 credit hours ( 3 hours clinical, 6 hours community practicum, 3 hours seminar)

Continuation of DH410, which is the prerequisite for this course. Clinical assignments, the community project, and theory from coursework in minor disciplines will be supplemented by readings and case problems designed to assist in applying theory to problems related to dental behaviors, especially those of special patient and nonpatient groups.

\section{Some problems}

Clearly, this hypothetical curriculum is not without its disadvantages, and it seems only fair to acknowledge its more severe shortcomings. The first, most obvious, question is whether it would pass muster with the Commission on Accreditation. I don't know whether it would pass muster with the Commission on Accreditation. I don't know whether a program with a nonclinical focus has ever been accredited - or even undergone evaluation for accreditation. That is the first obstacle.

The second dilemma is where the faculty to teach the wonderful synthesis and application courses (DH 350, DH 410, DH 420) will be found. Those versatile persons will need uncommon skills as facilitators of learning and as "interdisciplinarians." Not only will they need to have insights into what community dental hygiene practice has been and could be, but they also must have some competence in the behavioral and social sciences. The question becomes, should dental hygienists or social scientists be utilized in this role? No matter which choice is made, gaps in knowledge will require concentrated inservice or other education. Perhaps the courses should be team taught. But, in this era of stringent accountability in higher education, is it possible to justify the added expense of double faculty? Even if a team is not used, can it be argued convincingly that the individualized attention provided these students is essential and likely to bring benefits substantial enough to warrant the costs incurred?

The third big question mark is the students. Will they want to enroll in a program which does not fit the traditional connotation of "dental hygienist"? How many students will be uncomfortable with the flexibility - and therefore ambiguity — of this program? Although making decisions about the interests one truly has, which courses one will choose to take in the limited time available, and how courses must be sequenced is an integral part of liberal arts college experiences, it has not been necessary when one is enrolled as a dental hygiene student. However, making those commitments and decisions provides the opportunity for personal growth, and I am optimistic enough (and have encountered enough disillusioned, creative, intelligent, frustrated students) to believe that a program with the characteristics of undergraduate liberal arts education would attract persons who ultimately would greatly enrich the profession of dental hygiene. The combination of the purely academic and the vocational would seem to offer the best of both worlds to potential students, but might they perceive it that way?

Algo Henderson of the Center for Research and Development in Higher Education at the University of California-Berkeley makes a case for what he calls a "liberating education." 
It focuses on processes, and his lament over recent trends away from such an exploring education seem pertinent:

One result of their demands for relevance is the present tendency to vocationalize higher education. We are apprehensive about this trend because we believe that education needs to deal not solely with preparing people for work but also with facilitating personal growth, appreciation of the environment, analysis of contemporary society, knowledge of various cultures, scientific achievement and intellectual growth. ${ }^{11}$

\section{A Summary Rationale}

Fifteen years ago, a handful of "experts" was asked to consider the question, "Are dental hygienists overtrained and/or underutilized?" Although most respondents considered the plight of the clinical hygienist, one chose to be critical of another instance of underutilization, saying:

In dental public health programs, where there are many areas of activity in which the dental hygienist can serve, there still is widespread, wasteful underutilization of the potential capabilities of the trained public health dental hygienist. ${ }^{4}$

That critique is as valid today as it was in $\mathbf{1 9 6 0 .}$

But make no mistake. The health care system is changing: legislation is being passed; consumer expectations are increasing; new and enlightened provider attitudes are slowly evolving from the elitist, paternalistic ones of the past. Health care will become a right in practice as well as in theory. As it does, the health care milieu will be in a state of flux, and there will be a demand for health professionals who are not "cookbook followers." Whatever other skills might be required, surely the ones at the top of the list will be the abilities to assess what kind of dish is appropriate, determine what characteristics various potential ingredients might contribute to the final dish, then to create a recipe from scratch, selecting the ingredients and method of preparation most likely to produce the desired result. Persons with those skills cannot be educated by issuing a cookbook filled with classic recipes, and requiring substantial practice cooking those predetermined dishes. For the baccalaureate community dental hygienist, especially, an education should provide basic recipe-writing knowledge, and a frame of reference which legitimizes creative cooking.

The baccalaureate model for community dental hygiene just presented addresses those two requirements. Completing a minor in a behavioral or social science should provide the necessary knowledge, while the dental hygiene synthesis/application courses would supply the frame of reference and guided practice. Upper division courses in the behavioral and social sciences are a unique feature of baccalaureate institutions. Surely, it is prudent to capitalize on that strength and utilize the opportunity to do what no other institution can.

\section{BIBLIOGRAPHY}

1. American heritage dictionary of the English language. Boston, Houghton Mifflin, c1969. xlix +1550 p. (p. 270 ).

2. American higher education: Toward an uncertain future. Vol. I. Daedalus, 103:1-356, Fall 1974.

3. American higher education: Toward an uncertain future. Vol. II. Daedalus, 104:1-355, Winter 1975.

4. Are dental hygienists overtrained and/or underutilized? Am. A. Pub. Health Dent. Bul., 20:77-8, Fall 1960.

5. Brown, W. E., ed. Oral health, dentistry, and the American public; the need for an improved oral care delivery system. Norman, University Oklahoma Press, c1974. vii $+372 \mathrm{p}$.

6. Carnegie Commission on Higher Education. Higher education and the nation's health; policies for medical and dental education. New York, McGraw-Hill, 1970. x $128 \mathrm{p}$.

7. Carnegie Commission on Higher Education. College graduates and jobs; adjusting to a new labor market situation. New York, McGraw-Hill, 1973. ix +242 p.

8. Dunning, J. M. Principles of dental public health. 2nd ed. Cambridge, Harvard University Press, c1970. xiv +598 p.

9. Educational qualifications of public health dental hygienists. Am. J. Pub. Health, 46:1-8, July 1956. 
10. Feldman, K. A., and Newcomb, T. M. The impact of college on students; an analysis of 4 decades of research. San Francisco, Jossey-Bass, 1969, xi + 474 p.

11. Henderson, A. P., and Henderson, Jean G. Higher education in America; problems, priorities, prospects. San Francisco, Jossey-Bass, 1975. xii +282 p.

12. Ishida, Helen. Vocational interests of dental hygienists. Vocational Guidance Quar., 24:257-62, Mar. 1975.

13. Jencks, Christopher, and Riesman, David. The academic revolution. Garden City, NY, Doubleday, 1969. xx +580 p.

14. Malvitz, Dolores M., and Judge, Susan P. The survey of dental hygiene in Michigan: A preliminary report. Mich. Dent. Hyg. A. Bul., 5:8-9, Dec. 1975.

15. Schein, E. H. Professional education: Some new directions. New York, McGraw-Hill, cl972. xiii +163 p.

16. Young, W. O., and Striffler, D. F. The dentist, his practice, and his community. 2nd ed. Philadelphia, Saunders, cl969. xvi +346 p.

\section{Cosmetologists?}

Neither the American people nor those who represent them in government can be convinced of great importance for oral health when dental care is promoted primarily for its effect on cosmetics. Dentists can be sure that any program of national health insurance, which comes from either private dental practice or from the public, will contain little to benefit oral health until dental treatment is promoted as a service for health. Dentists, too long, have left the true story of oral health to researcher and teachers only. The time has come for all dentists "to emphasize the positive."

-George W. Teuscher in the Journal of Dentistry for Children, March-April, 1976. (KAE)

\section{The Lighter Side of News From the Hill}

Helen Dewar, Washington Post staff writer, reports that Senator J. Glenn Beall (citing $\$ 4$ billion a year as the cost to the government to support regulatory agencies, as well as 130 million man-hours required of business and individuals to fill out required forms) has announced his intention to introduce a bill that would permit Congress to veto federal regulations before they are imposed. Examples of what he would stop - A 22-page Consumer Product Safety Commission regulation on standards for construction and use of swimming pool slides, including instructions on the proper position for a belly slide; an Occupational Safety and Health Administration requirement that trucks used on construction sites have back-up beepers, which drew protests from environmental protection officials because the beepers were too noisy; $\$ 30$ million reportedly spent by Goodyear Tire and Rubber Co. (equivalent to the annual salary of 3,400 of their employees) to comply with federal regulations in 1974; automobile seatbelt interlock system ( $\$ 100$ per car) eventually repealed. When he made this announcement, Beall was surrounded by 60,000 pages of regulatory documents for 1975, which, if put in one pile, would total 10 feet in height.

-In University Michigan Reporter for Mar. 1, 1976. 